\title{
Investigasi Tegangan Lebih Transien akibat Sambaran Petir pada Gardu Induk 150 kV
}

\author{
Setyo Adi Nugroho ${ }^{1^{*}}$ \\ ${ }^{1}$ ITS PKU Muhammadiyah Surakarta \\ ${ }^{1}$ setyo0623@gmail.com* \\ *corresponding author
}

\begin{tabular}{|c|c|}
\hline ABSTRACT & Article Info \\
\hline $\begin{array}{l}\text { Electrical energy is the essential things that we need in any aspect of the like } \\
\text { industry, hospital, school, etc. Therefore, the transmission of electrical power has } \\
\text { to be reliable and continuous. However, those ideal condition is hard to achieve } \\
\text { in daily basis because if disruption like lightning impulse. Arrester is a device } \\
\text { that prevents or stops overvoltage disruption. In this research, two kinds of } \\
\text { arrester are compared and modeling substation devices using simulation } \\
\text { software ATPDraw. The simulation result shows us that the Q150NA121A } \\
\text { arrester has outstanding performance with an overvoltage value of } 454 \mathrm{kV} \text {. In the } \\
\text { other side, Q150NB121A arrester has overvoltage value at } 579 \mathrm{kV} \text {. }\end{array}$ & \multirow[t]{3}{*}{$\begin{array}{r}\text { Article history } \\
\text { Received: March } 10^{\text {th }}, 2021 \\
\text { Revised: May } 28^{\text {th }}, 2021 \\
\text { Accepted: May } 30^{\text {th }}, 2021 \\
\text { Keywords } \\
\text { arrester, } \\
\text { ATPDraw, } \\
\text { lightning, } \\
\text { overvoltage. }\end{array}$} \\
\hline ABSTRAK & \\
\hline $\begin{array}{l}\text { Energi listrik merupakan kebutuhan yang sangat penting pada setiap sektor } \\
\text { seperti pendidikan, industri, rumah sakit, dan lain-lain. Oleh sebab itu penyaluran } \\
\text { energi listrik diharapkan memiliki kontinyuitas dan kehandalan yang tinggi, } \\
\text { namun dalam praktiknya hal tersebut sulit tercapai disebabkan karena berbagai } \\
\text { macam gangguan salah satunya gangguan tegangan lebih impuls petir. Arester } \\
\text { adalah peralatan yang saat ini banyak digunakan secara luas untuk mengurangi } \\
\text { dan mencegah gangguan tegangan lebih. Pada penelitian ini dua tipe arester } \\
\text { dibandingkan serta memodelkan peralatan yang ada pada gardu induk dengan } \\
\text { menggunakan simulasi ATPDraw. Hasil simulasi menunjukkan bahwa arester } \\
\text { tipe Q150NA121A mempunyai kinerja yang sangat baik dengan nilai tegangan } \\
\text { lebih sebesar } 454 \mathrm{kV} \text {. Sedangkan untuk arester tipe Q150NB121A nilai tegangan } \\
\text { lebih sebesar } 579 \mathrm{kV} \text {. }\end{array}$ & \\
\hline
\end{tabular}

\section{PENDAHULUAN}

Gardu induk merupakan komponen penting pada sebuah sistem tenaga listrik mengingat fungsinya sebagai penyuplai energi listrik dari pusat pembangkit listrik ke konsumen dan sebagai penghubung jaringan interkoneksi, gardu induk dapat di klasifikasikan berdasarkan besaran tegangannya, pemasangan peralatannya, dan fungsinya (S. A. Ali, 2013). Perusahaan listrik negara di Indonesia yaitu PT. PLN menggunakan sistem tegangan $150 \mathrm{kV}$ dalam menyalurkan energi listriknya ke gardu-gardu induk melalui sistem transmisi udara (overhead).

Suplai energi listrik ke konsumen diharapkan memiliki kontinyuitas dan kehandalan yang tinggi oleh sebab itu berbagai upaya telah banyak dilakukan agar hal tersebut dapat tercapai (M. B. Nappu, A. Arief, and S. M. Said, 2018). Beberapa gangguan yang dapat mempengaruhi suplai energi listrik antara lain adalah gangguan tegangan lebih akibat 
sambaran petir yang dapat menyebabkan kenaikan tegangan sistem sehingga akan merusak sistem isolasi dan merusak peralatan.

Peralatan untuk sistem $150 \mathrm{kV}$ dirancang dengan kekuatan isolasi dasar/basic insulation level (BIL) sebesar $650 \mathrm{kV}$ (standar IEEE C62.22, 2013). Arester adalah alat proteksi yang banyak digunakan untuk mengurangi tegangan lebih dan mencegah kerusakan akibat sambaran petir. Penelitian yang telah dilakukan sebelumnya menganalisis pemasangan arester pada saluran transmisi untuk evaluasi bacflashover, analisis pemasangan arester pada sisi gardu induk belum dilakukan (J. Sardi, J. Ong, and C. Chian, 2010). Sehingga pada penelitian ini akan dilakukan analisis pemasangan arester pada gardu induk dengan beberapa tipe yang berbeda sehingga dapat dipilih tipe arester yang tepat.

\section{METODE}

Pada penelitian ini akan dibandingkan dua tipe arester berbeda yang diterapkan pada gardu induk PLN $150 \mathrm{kV}$ untuk mengetahui kinerja dari masing-masing arester dalam kordinasi proteksi berdasarkan standar IEEE C62.22 BIL peralatan $150 \mathrm{kV}$ yaitu $650 \mathrm{kV}$. Arus impuls petir diterapkan untuk menguji kinerja arester tersebut menggunakan perangkat lunak ATPDraw, berdasarkan standar IEC bentuk gelombang impuls petir yaitu $1,25 \times 50$ ms (S. A. Hosseini, M. Mirzaie, and T. Barforoshi, 2015).

Tabel 1. Spesifikasi Arester

\begin{tabular}{cccc}
\hline Tipe & $\begin{array}{c}\text { Tegangan } \\
(\mathrm{Kv})\end{array}$ & $\begin{array}{c}\text { BIL } \\
(\mathrm{kV})\end{array}$ & $\begin{array}{c}\text { Panjang } \\
(\mathrm{m})\end{array}$ \\
\hline Q150NA121A & 150 & 669 & 1,798 \\
Q150NB121A & 150 & 788 & 2,07 \\
\hline
\end{tabular}

Berikut ini kontruksi dari kedua buah model arrester (Q150NA121A dan Q150NB121A) ditunjukkan oleh Gambar 1.
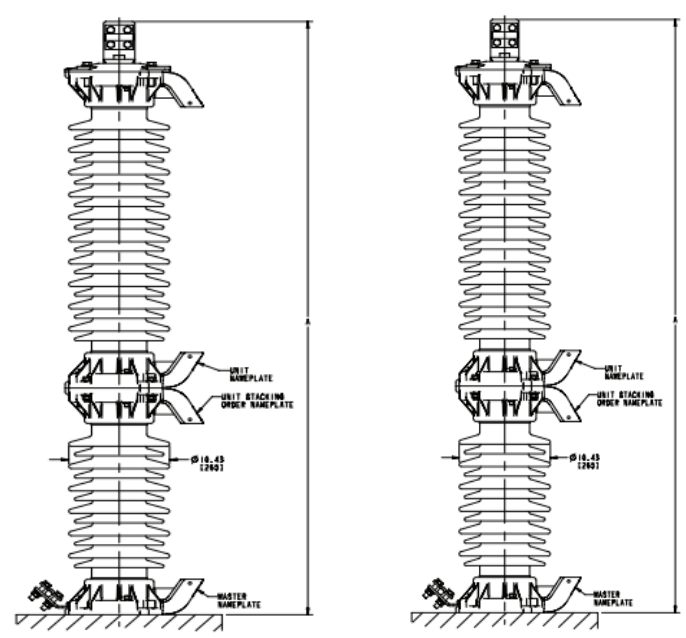

\section{Gambar 1. Konstruksi Arester (Q150NA121A dan Q150NB121A)}

Spesifikasi ketinggian dari setiap konduktor yaitu konduktor fasa dan konduktor pentanahan (ground) seperti yang ditunjukan pada tabel 2 diperlukan pada penelitian ini, supaya dapat diketahui lonjakan tegangan tertinggi pada tiap fasa berdasarkan perbedaan ketinggiannya.

Tabel 2. Ketinggian Setiap Konduktor

\begin{tabular}{lcc}
\hline \multicolumn{1}{c}{ Parameter } & Nilai & Satuan \\
\hline Tinggi Ground Wire & 40,55 & meter \\
Tinggi Fasa R & 38,55 & meter \\
Tinggi Fasa S & 34,85 & meter \\
Tinggi Fasa T & 31,15 & meter \\
\hline
\end{tabular}

Setelah semua data dikumpulkan maka langkah berikutnya adalah memodelkan setiap peralatan yang ada pada gardu induk $150 \mathrm{kV}$. Nilai pentanahan pada penelitian ini di kondisikan konstan pada nilai 0,2 Ohm. Pengukuran tegangan lebih dilakukan pada sisi primer transformator daya dan arester diletakan dengan jarak 7 meter sesuai dengan pengukuran di lapangan. 


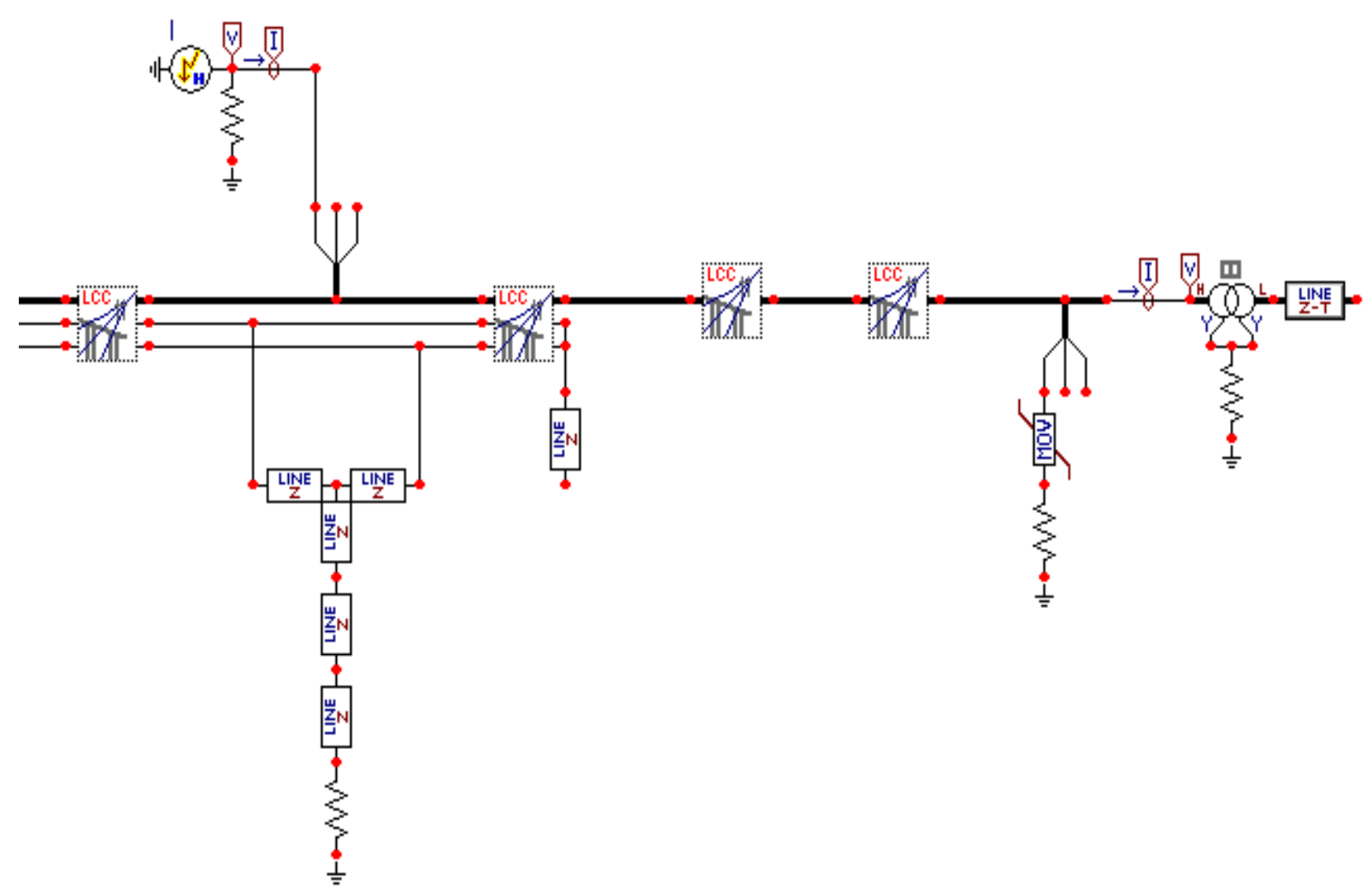

Gambar 2. Pemodelan Sistem Pada ATPDraw

Gambar 2 adalah pemodelan dari setiap peralatan sistem tenaga listrik yang ada pada gardu induk maupun sistem transmisi. Arus petir disimulasikan dengan model Heidler yang diparalel dengan resistor $400 \mathrm{Ohm}$ dan menara transmisi $150 \mathrm{kV}$ dimodelkan dengan menggunakan model menara JMarti.

\section{HASIL DAN PEMBAHASAN}

\section{A. Analisis Tegangan Lebih Tanpa Terpasang Arester}

Investigasi pertama pada penelitian ini yaitu sambaran petir pada konduktor tanpa terpasangnya arrester di gardu induk atau transformator daya dengan nilai arus petir sebesar $10 \mathrm{kA}$.

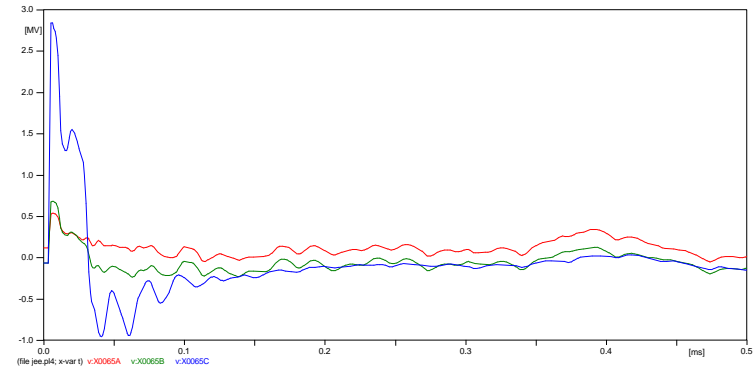

Gambar 3. Tegangan Lebih Tanpa Terpasang Arester

Berdasarkan hasil simulasi seperti yang ditunjukkan Gambar 3, tegangan lebih yang melewati transformator daya nilainya melebihi dari BIL peralatan, fasa $\mathrm{C}$ mengalami lonjakan tegangan paling tinggi dibandingkan dengan fasa lainnya yaitu sebesar $2,83 \mathrm{MV}$, sedangkan fasa A dan B sebesar $537 \mathrm{kV}$ dan $682 \mathrm{kV}$. Kondisi ini dapat menyebabkan kerusakan pada transformator daya sehingga perlu dilakukan pengurangan dan pencegahan tegangan lebih akibat sambaran petir tersebut. 
B. Analisis Tegangan Lebih dengan Arester Tipe Q150NA121A

Investigasi berikutnya adalah melakukan pemasangan peralatan arester pada terminal transformator yaitu untuk fasa $\mathrm{C}$, karena pada fasa tersebut lonjakan tegangan terjadi sangat tinggi. Tipe arester yang akan dipasang yaitu Q150NA121A dengan rating tegangan $150 \mathrm{kV}$. Karakteristik non-linier arester tersebut didapatkan dengan berpedoman pada kurva yang diusulkan oleh IEEE WG 3.4.11 yang dikalikan dengan level tegangan impuls petir ketika bernilai 10 kA (I. W. G. 3.4.11. ,1992).

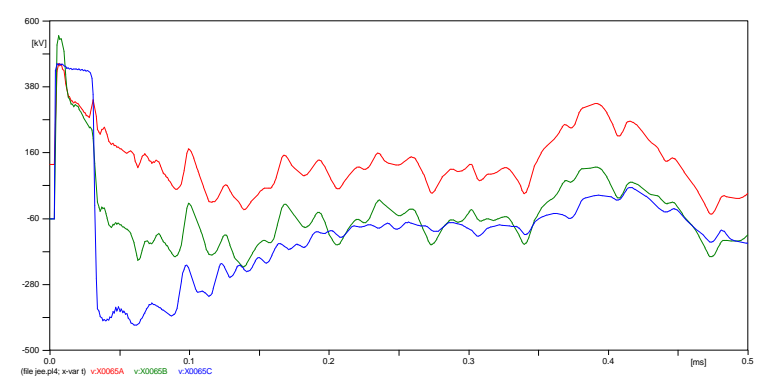

Gambar 4. Tegangan Lebih Saat Terpasang Arester (Q150NA121A)

Berdasarkan hasil simulasi seperti yang ditunjukkan oleh Gambar 4, tegangan lebih pada terminal transformator berkurang sampai dibawah nilai standar BIL. Tegangan lebih pada fasa $\mathrm{C}$ menjadi sebesar $454 \mathrm{kV}$, sedangkan pada fasa A dan B sebesar $457 \mathrm{kV}$ dan $551 \mathrm{kV}$. Sehingga dapat dikatakan bahwa transformator aman dari tegangan lebih impuls petir.

\section{Analisis Tegangan Lebih dengan Arester} Tipe Q150NB121A

Investigasi yang terakhir yaitu melakukan pemasangan arester seperti investigasi sebelumnya tetapi dengan tipe arester yang berbeda yaitu tipe Q150NB121A. Hasil simulasi dapat dilihat pada Gambar 5 berikut ini.

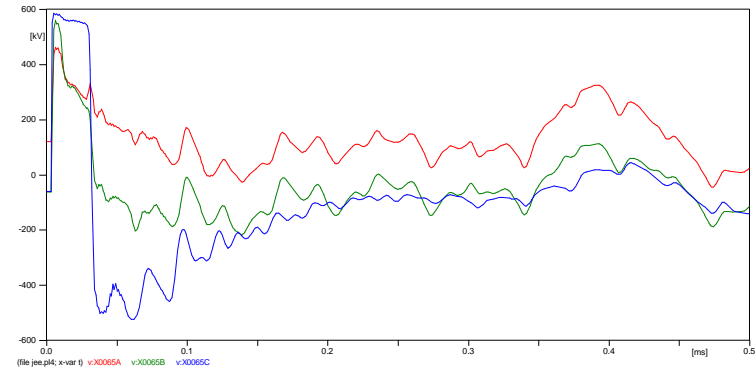

Gambar 5. Tegangan Lebih Saat Terpasang Arester (Q150NB121A)

Tegangan lebih yang dihasilkan arester tipe Q150NB121A menunjukkan hasil yang lebih besar dibandingkan dengan tipe arester Q150NA121A yaitu pada fasa C sebesar 579 $\mathrm{kV}$ sedangkan untuk fasa A dan B sebesar 462 $\mathrm{kV}$ dan $559 \mathrm{kV}$. Dari ketiga investigasi yang telah dilakukan, dapat disajikan dalam bentuk grafik seperti Gambar 6 berikut.

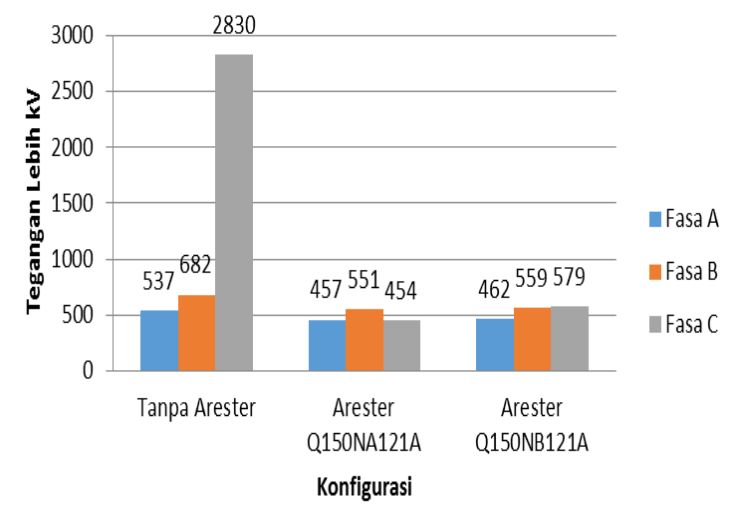

Gambar 6. Grafik Perbandingan Tegangan lebih Setiap Arester

\section{SIMPULAN}

Tujuan dari penelitian ini adalah untuk membandingkan kinerja dari arester tipe Q150NA121A dan arester tipe Q150NB121A menggunakan perangkat simulasi ATPDraw. Dari hasil penelitian dapat diambil beberapa kesimpulan sebagai berikut:

1. Pemasangan arester pada terminal transformator dapat mengurangi tegangan lebih sangat signifikan, terutama pada fasa yang mengalami sambaran petir pada penelitian ini yaitu fasa $\mathrm{C}$. 
2. Penggunaan arester tipe Q150NA121A dapat mengurangi tegangan lebih mencapai 43,17\% dari standar BIL sedangkan untuk tipe arester tipe Q150NB121A hanya mencapai $12,26 \%$ dari standar BIL. Sehingga sangat disarankan pada gardu induk $150 \mathrm{kV}$ untuk memasang arester dengan tipe yang tepat agar tegangan lebih yang diakibatkan oleh sambaran petir tidak melebihi nilai BIL peralatan.

\section{DAFTAR RUJUKAN}

IEEE Std C62.22a, 2013. IEEE Guide for the Application of Metal-Oxide Surge Arresters for Alternating-Current Systems. IEEE.

I. W. G. 3.4.11. 1992. Protective Devices Committee's subcommittee. Trans. Power Deliv., vol. 7, no. 1, pp. 302-309.

J. Sardi, J. Ong, and C. Chian. 2010. "Evaluation of Surge Arrester
Requirement for Overhead Transmission Line using Electromagnetic Transient Program," IEEE Int. Conf. Power Energy, pp. 985-988.

M. B. Nappu, A. Arief, and S. M. Said. 2018. The Placement of the Transmission Lightning Arrester ( TLA ) at $150 \mathrm{kV}$ Network using Fuzzy Logic. pp. 347352.

S. A. Ali. 2013. Design of lightning arresters for electrical power systems protection. Adv. Electr. Electron. Eng. vol. 11, no. 6, pp. 433-442, doi: 10.15598/aeee.v11i6.661.

S. A. Hosseini, M. Mirzaie, and T. Barforoshi. 2015. Impact of Surge Arrester Number and Placement on Reliability and Lightning Overvoltage Level in High Voltage Substations. Int. J. Electr. Power Energy Syst., vol. 65, pp. 146158, doi: 10.1016/j.ijepes.2014.09.037. 